\title{
A new generation
}

\author{
Thomas W. Jeffries
}

(C) U.S. Government 2010

In May of 1978, a small group of Department of Energy scientists led by Charles D. Scott began meeting at the Riverside Motor Lodge in Gatlinburg Tennessee to discuss biotechnologies for the production of fuels and chemicals from biomass. There had been three previous ad hoc meetings by diverse groups, but this was the first that established a regular attendance.

The annual Symposium on Biotechnology for Fuels and Chemicals, or simply the Fuels and Chemicals meeting as it is often known to its regulars, has grown from a community of eclectic believers into the largest international meeting of its kind. From fewer than 75 in early meetings, SBFC attendance has increased more than ten fold.

After oscillating for many years between meetings sponsored by the Oak Ridge National Laboratory and the National Renewable Energy Laboratory in Golden, Colorado, the SBFC has become an international gathering place with venues around the US. The Society for Industrial Microbiology took over logistics for the SBFC beginning with the 28th Symposium in 2006 and has since managed meetings in Nashville, Denver, New Orleans and San Francisco.

At the 32nd Symposium, which was held in Clearwater Beach, Florida from April 19-22, 2010, more than 850 engineers, scientists, policy makers, investors and innovators from 27 countries participated in an intense exchange that included 80 lectures, 3 panels, and over 400 poster presentations.

Topics included sustainability and land use, biomass recalcitrance, development of new or improved biomass sources, better enzymatic and microbial catalysts, advances

T. W. Jeffries ( $\square)$

Madison, WI, USA

e-mail: twjeffri@wisc.edu in the development of hydrocarbon and algae-based biofuels, progress in biorefinery deployment and infrastructure, and recent improvements in pretreatment, fractionation and related separations technologies.

Along with scientific and technical presentations, an industry for the production of clean, renewable biofuels from agricultural and forest feedstocks has begun to emerge. Centered on the use of plant biomass rather than foodstuffs the SBFC has led the way in publicizing biotechnologies that will convert residues and wastes rather than food and feed.

The growth in topics and participants along with increased interest in using biotechnology to produce renewable fuels and chemicals have brought many more opportunities and challenges in the publication of the SBFC research reports. The pace of change has increased as commercial implementation has ensued, and at the same time, the breadth of topics has made incorporation of papers into a coherent proceedings volume increasingly difficult.

Proceedings from the symposia were originally published as special issues of Biotechnology and Bioengineering. Starting with the 9th Symposium in 1987, the outlet shifted to Applied Biochemistry and Biotechnology. At the 32nd Symposium this year, SBFC leadership decided to stop publishing presentation manuscripts in a stand-alone proceedings volume. Instead, authors have been encouraged to submit manuscripts of their work presented at the SBFC for publication in the official journal of the SIM, the Journal of Industrial Microbiology and Biotechnology.

Starting imminently and continuing in an annual cycle, $J I M B$ will publish high-quality, peer-reviewed papers based on research presentations from the Symposia as they are received, reviewed and edited. Papers will appear in the most appropriate sections of the Journal and will be identified as originating from the SBFC. 
Many high quality presentations are made at the Symposium and in recent years various engineering, microbiological, economics and molecular biological journals have been outlets for SBFC papers. The editors invite prospective SBFC authors to consider JIMB as an excellent outlet for their best and most appropriate work.
The JIMB Editors and SBFC Organizers will strive to serve the best interests of the research community by emphasizing originality, quality, significance and timeliness in publishing manuscripts from the Symposium. As such, we look forward to continuing its strong traditions. 